Thorax (1976), 31, 765.

\title{
Symptomatic mitral myxomatous transformation in the elderly
}

\author{
P. COLLINS, R. E. COT TON, and R. S. DUFF \\ Departments of Cardiology and Pathology, City Hospital, Nottingham
}

\begin{abstract}
Collins, P., Cotton, R. E., and Duff, R. S. (1976). Thorax, 31, 765-770. Symptomatic mitral myxomatous transformation in the elderly. The clinical and pathological features of four patients with intractable heart failure, due to myxomatous change in the mitral valve, are described. It is suggested that this change may represent a response of ageing connective tissue to mechanical stress.
\end{abstract}

The integrity of the mitral valve can be impaired by a variety of pathological processes; the clinical picture depends upon the suddenness with which mitral incompetence develops and the adequacy of the circulatory adjustments (Raftery, Oakley, and Goodwin, 1966). Residual rheumatic heart disease is found in the elderly, although less commonly than in the general population; and of those with mitral valve disease two-thirds have dominant regurgitation (Caird, 1963). However, mitral incompetence should not be labelled as rheumatic without supporting evidence, as a proportion of cases result from other causes. Myxomatous (mucoid) degeneration of the mitral valve is one such condition, in which there is disruption of the normal collagenous architecture of the valve and its replacement by gelatinous material which stains metachromatically. This results in thickened, nodular, voluminous cusps which may prolapse into the left atrium during ventricular systole (Bittar and Sosa, 1968).

The clinical importance of this change in the elderly became apparent following the description of two such patients in 1958 by Fernex and Fernex. Pomerance (1969) reported this change in $1 \%$ of adult necropsies, with an average age incidence of 73.6 years, but thought it to be of little clinical significance.

The purpose of this paper is to describe four elderly patients who had severe and fatal mitral incompetence shown to be due to gross myxomatous change in their mitral valves.

\section{CASE REPORTS}

CASE 1 A 76-year-old woman was admitted to hospital with orthopnoea and interscapular pain of five days' duration.
She was dyspnoeic, sweating, and cyanosed; the heart was irregular, with a ventricular rate of $104 / \mathrm{min}$; the blood pressure was $140 / 70 \mathrm{mmHg}$. The jugular venous pressure was raised $2 \mathrm{~cm}$. Auscultation revealed a protodiastolic gallop, and a harsh apical pansystolic murmur accompanied by a thrill. Rales were heard throughout both lung fields. The electrocardiogram showed sinus rhythm with supraventricular ectopic beats and left anterior heart block (Fig. 1). The chest radiograph showed a slight increase in the transverse diameter of the heart, without undue prominence of the left atrium in the straight film. Despite treatment with intravenous and oral frusemide, together with digitalis, she died four days after admission.

At necropsy the heart weighed $340 \mathrm{~g}$. There was slight dilatation of the left atrium and early left ventricular hypertrophy. The papillary muscles of the left ventricle were normal and there was no suspicion of infarction or scarring of the left ventricular myocardium. The coronary arteries showed mild atheroma but there was no occlusion. The mitral valve cusps were thickened, nodular, and opalescent. The anterior cusp was voluminous and was ballooned into the left atrium (Fig. 2). The chordae were intact. Histology of the valve cusps showed gross myxomatous change.

CASE 2 A 65-year-old woman had acute dyspnoea for one week and central chest pain for some hours before admission to hospital. She was breathless, sweating, and cyanosed; the heart was regular at $120 / \mathrm{min}$, and the blood pressure 160 / $90 \mathrm{mmHg}$. The jugular venous pressure was raised $4 \mathrm{~cm}$ and there was pitting oedema of the ankles. There was an apical pansystolic murmur, 


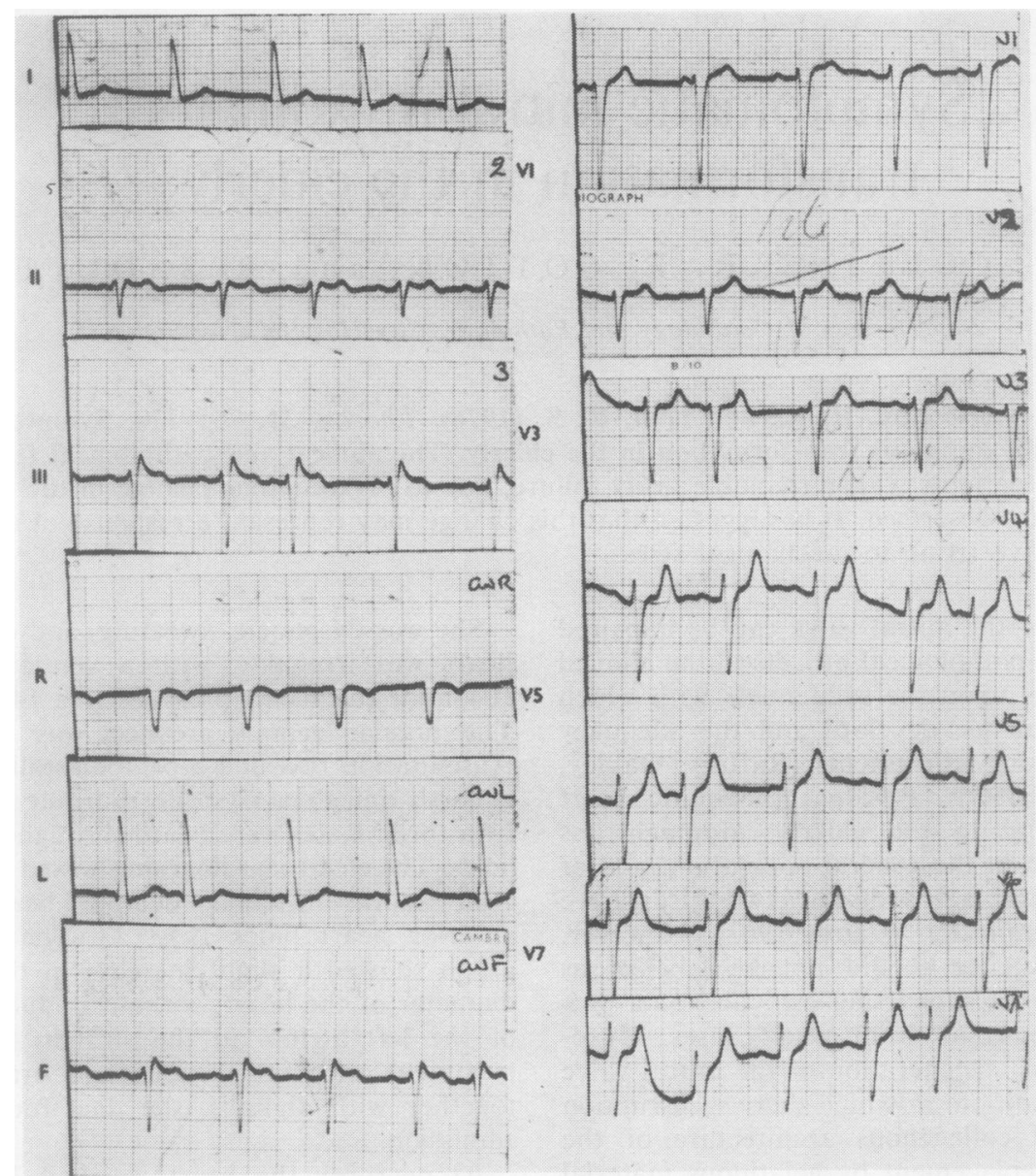

FIG. 1. The ECG of case 1 showing sinus rhythm with supraventricular extrasystoles and left anterior heartblock.

accompanied by a thrill, and a protodiastolic gallop. Rales were heard throughout both lung fields. The electrocardiogram showed sinus rhythm, clockwise rotation, left axis deviation, and left ventricular hypertrophy. ST segment depression was present in the standard limb leads and V5. The chest radiograph showed a moderate increase in heart size without prominence of the left atrium in the straight film. She was treated with digoxin and frusemide but died on the third day after admission.

At necropsy the heart weighed $460 \mathrm{~g}$ and showed dilatation of the left atrium and biventricular hypertrophy. There was no macroscopic evidence of myocardial infarction or of myocardial fibrosis. The mitral valve cusps were nodular, thickened, and opalescent. The posterior cusp was prolapsed into the left atrium. Rupture of one group of its chordae had occurred adjacent to $\frac{D}{0}$ their insertion on the papillary muscle (Fig. 3). Histology of the valve revealed gross myxomatous of change. There was no evidence of significant $N$ coronary artery disease.

CASE 3 A 67-year-old man was sent into hospital with cardiac failure and a history of exertional dyspnoea over the preceding three years.

He was breathless and cyanosed; the heart was: irregular with a ventricular rate of around $95 / \frac{0}{0}$ min, and the blood pressure $120 / 80 \mathrm{mmHg}$. The $\frac{}{\mathbb{1}}$ jugular venous pressure was raised to the angle $\frac{O}{\mathbb{D}}$ of the jaw and there was gross pitting oedema 


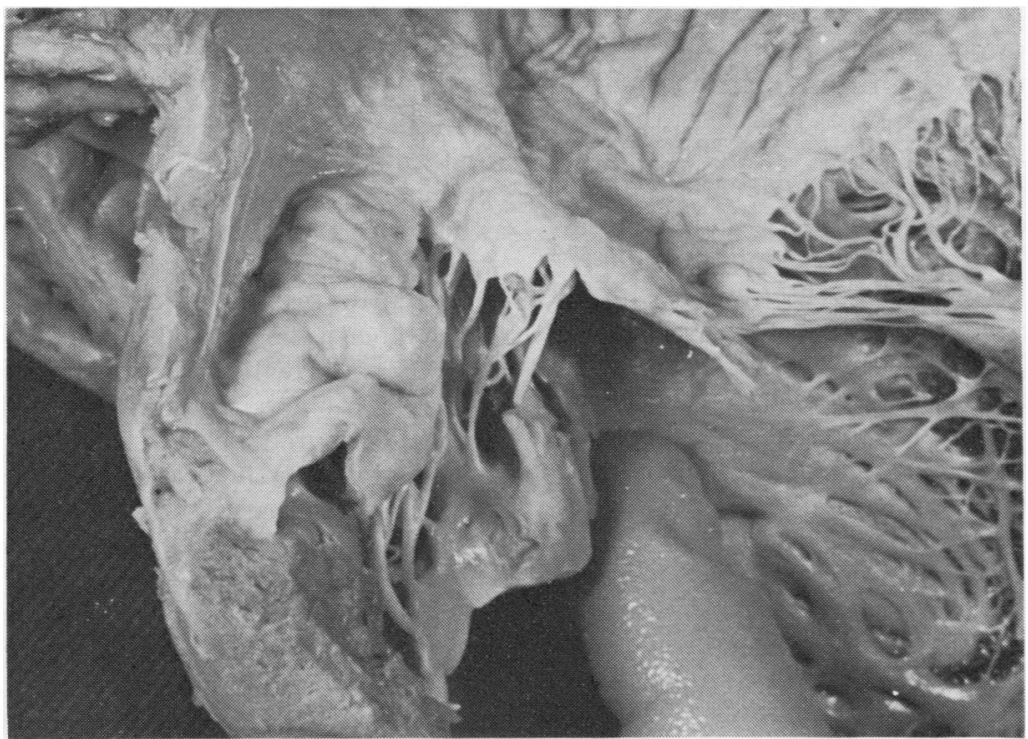

FIG. 2. Case 1. The mitral valve shows ballooning of the anterior leaflet (left), which appears coarsely nodular and thickened. The posterior leaflet (right) shows similar nodularity and thickening but to a lesser degree.

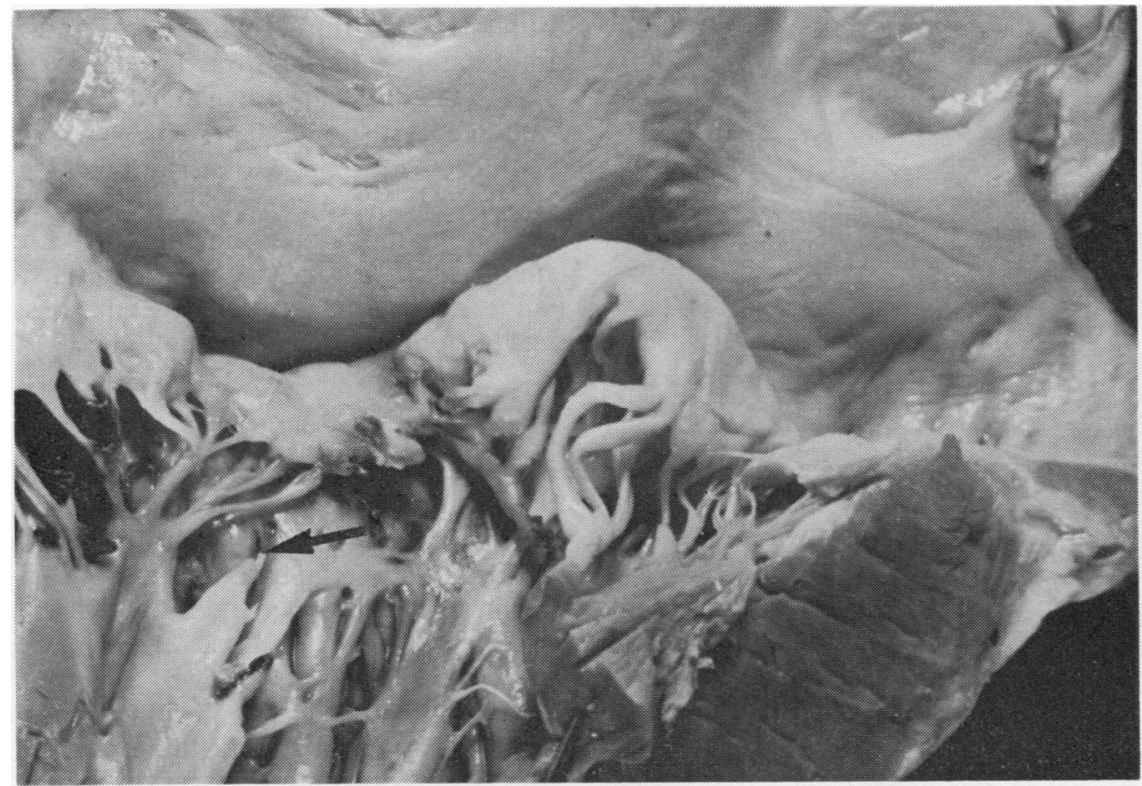

FIG. 3. Case 2. The posterior cusp of mitral valve is nodular and thickened due to myxomatous change. The arrow points to the site of chordal rupture. 
of the legs. Auscultation revealed an apical pansystolic murmur and a third heart sound. Highpitched rhonchi were heard throughout both lungs.

The electrocardiogram showed atrial fibrillation, clockwise rotation, and left axis deviation. The $T$ waves were inverted in leads I, II, and V5 to V7.

The cardiac failure did not respond to intensive treatment with digoxin and frusemide, and death occurred on the eleventh day.

At necropsy the heart was enlarged $(600 \mathrm{~g})$ and generally dilated and showed biventricular hypertrophy. The myocardium showed no evidence of fibrosis or infarction. The coronary arteries were atheromatous but there was no coronary artery occlusion.

The mitral valve cusps were thickened, nodular, and opalescent but were not ballooned, and their chordae were intact (Fig. 4). There was considerable dilatation of the mitral annulus which

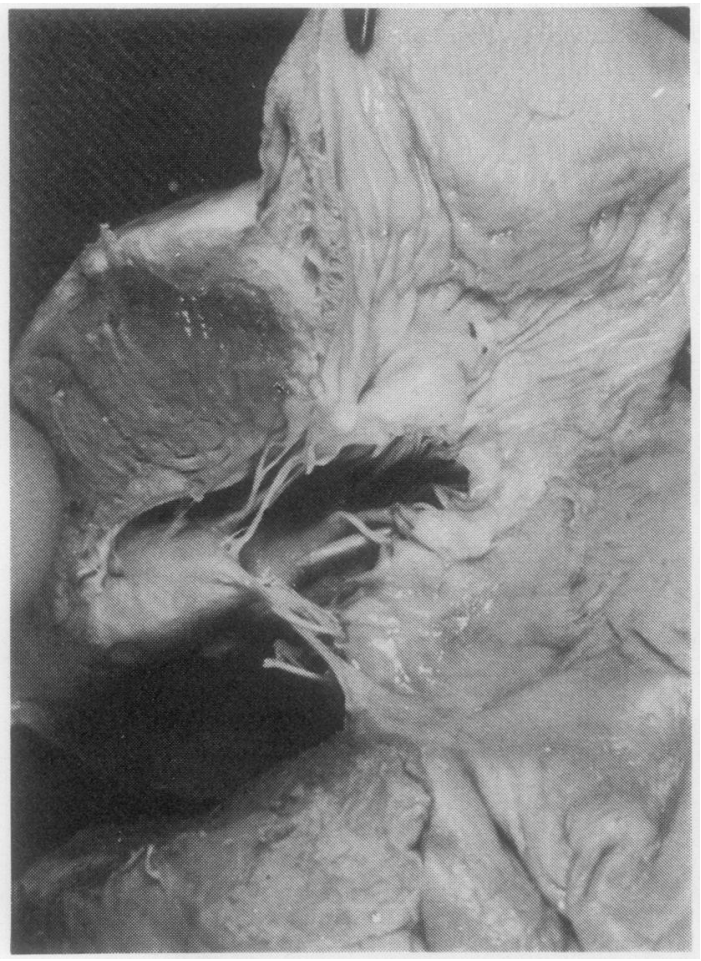

FIG. 4. Case 3. The mitral valve leaflets have the characteristic thickened, nodular appearance of myxomatous change, but in this patient the mitral incompetence was considered to be due to dilatation of the mitral annulus. admitted four fingers. Histology of the valve apparatus showed myxomatous change.

CASE 4 A man of 71 gave a history of dyspnoea $\mathbb{\nabla}$ and ankle oedema of sudden onset three months previously. $\mathrm{He}$ was admitted to another hospital ${ }^{\text {क }}$ where he was found to have congestive heart $\vec{\circ}$ failure and mitral incompetence. He recovered $\overrightarrow{\vec{\omega}}$ sufficiently to be discharged after three weeks. Subsequently he was admitted to the Nottingham $\overrightarrow{\vec{x}}$ City Hospital with a recurrence of symptoms and $\dot{\omega}$ a history of a recent fall, which had resulted in several fractured ribs.

On admission he was dyspnoeic and cyanosed; ठิ the heart was irregular at $105 / \mathrm{min}$; blood pressure $\mathrm{O}$ $120 / 80 \mathrm{mmHg}$. The jugular venous pressure was raised, and he had ankle oedema. There was an 0 apical pansystolic murmur accompanied by a thrill. The lung bases were dull to percussion. The $\frac{\Phi}{3}$ electrocardiogram showed atrial fibrillation but $\underset{\mathbb{D}}{\mathcal{D}}$ little else of note. The chest radiograph showed marked cardiac enlargement and bilateral pleural effusions.

Despite treatment with digoxin and frusemide he died on the third day after admission.

At necropsy the heart was considerably enlarged $(860 \mathrm{~g})$. The left atrial appendage contained antemortem thrombus. The left atrium was $\stackrel{\mathbb{Q}}{\stackrel{2}{2}}$ dilated and there was biventricular hypertrophy. $\overrightarrow{\vec{F}}$ The myocardium, although hypertrophied, was otherwise normal. The coronary arteries were moderately atheromatous but there was no occlu-o sion. The mitral valve cusps were thickened, nodular, and opalescent. The posterior cusp was $\underline{0}$ prolapsed into the left atrium, and a number of $\underset{x}{\Perp}$ its chordae were ruptured. In addition, there was $\dot{0}$ an anomalous insertion of the chordae on to the inferior surfaces of the cusps. Histology of the $\delta$ valve apparatus showed myxomatous change.

The lungs showed multiple areas of infarction. 을

\section{DISCUSSION}

In none of the above patients was there a past ज history of rheumatic fever nor was there any $N$ postmortem evidence of chronic rheumatic heart $N$ disease, bacterial endocarditis or significant $\frac{\omega}{\sigma}$ coronary artery or myocardial disease. There was no family history of cardiac disease, and none of the patients was known to have had cardiac trouble in adult life before the terminal illness. None of them showed the obvious features of Marfan's syndrome.

Focal mitral myxomatous change in the elderly $\frac{\text { के }}{\mathrm{O}}$ has been recognized for many years (Dewitzky, 음 
1910; Felsenreich and von Weisner, 1915; Böhmig and Krückeberg, 1934). This localized form is not uncommon and is thought to increase in incidence with advancing years. It is more common in the posterior than the anterior cusp and is mainly confined to the distal half of the valve fibrosa (Pomerance, 1967). Focal myxomatous change per se appears to have no haemodynamic significance.

The earliest reports of gross and symptomatic mitral myxomatous change have shown an association with the Marfan syndrome, often with involvement of the tricuspid and pulmonary valves (Weill, 1932; Tobin, Bay, and Humphreys, 1947; Tung and Liebow, 1952; McKusick, 1955; Sinclair, Kitchin, and Turner, 1960; Berenson and Geer, 1963; Shankar et al., 1967).

Read, Thal, and Wendt (1965) designated nine cases of valvular myxomatous change as the 'floppy valve syndrome'. His patients had an age range of 15 to 49 years. Many had features or a family history of Marfan's syndrome, of which he considered this condition to be a forme fruste.

Pomerance (1965) described the necropsy findings in patients over the age of 75 , and compared those who had heart failure before death with those who had clinically normal hearts. Six per cent of those in failure had mitral myxomatous (mucoid) change compared with $3 \%$ in the control group. However, all those in heart failure had multiple pathological lesions which could have been significant.

There is little doubt that in many patients myxomatous mitral valve changes do not produce either clinical abnormality or disturbance of cardiac function. However, our patients illustrate that at the other end of the spectrum this lesion can produce severe mitral incompetence which may be rapidly fatal.

The mechanism of mitral incompetence in our patients was ruptured chordae (two), prolapse of a deformed cusp (one), and dilatation of the mitral annulus (one). Others have found associated loss of valve substance, shortening of the chordae, nodularity of the cusps, and bacterial endocarditis.

The pathogenesis of mitral myxomatous change is uncertain; some authors regard it as an ageing phenomenon (Fernex and Fernex, 1958), whereas Pomerance (1969) considered it to be a nonspecific change resulting from a variety of possible aetiological factors.

It therefore seems that patients who have this change may be divided into two groups: (1) a younger group who have Marfan's syndrome or its forme fruste, and (2) a group of morphologically normal but older persons. Clearly, in the first group, this change cannot represent an ageing phenomenon but is presumed to be related to a developmental anomaly of the mesoderm.

The mitral valve is the commonest site at which myxomatous change occurs in both groups of patients. It is also the valve which is subject to the most haemodynamic stress.

One factor in the pathogenesis of myxomatous change may be the response of ageing valvular connective tissue to mechanical stress, and its premature appearance in patients who have Marfan's syndrome may reflect an increased susceptibility due to an inherent defect of connective tissue.

There were no clinical features in our patients that enable this change to be distinguished during life from other causes of mitral incompetence, nor did we find specific electrocardiographic changes such as those described in relation to the mitral valve abnormalities of Marfan's syndrome (Bowers, 1969). However, this condition should be considered in the differential diagnosis of mitral incompetence in the elderly, especially if this is thought to be of recent onset and of severe degree.

\section{REFERENCES}

Berenson, G. S. and Geer, J. C. (1963). Heart disease in the Hurler and Marfan syndromes. Archives of Internal Medicine, 111, 58.

Bittar, N. and Sosa, J. A. (1968). The billowing mitral valve leaflet. Circulation, 38, 763.

Böhmig, R. and Krückeberg, B. (1934). Untersuchungen über die diagnostischen Schwierigkeiten bei chronischen Veränderungen der Mitralklappe. Beiträge zur pathologischen Anatomie und zur allgemeinen Pathologie, 94, 163.

Bowers, D. (1969). Primary abnormalities of the mitral valve in Marfan's syndrome: electrocardiographic findings. British Heart Journal, 31, 676.

Caird, F. I. (1963). Heart disease in old age. Postgraduate Medical Journal, 39, 408.

Dewitzky, W. (1910). Ueber den Bau die Entstehung verschiedener Formen der chronischen Veraenderungen in den Herzklappen. Virchows Archiv für pathologische Anatomie und Physiologie und für klinische Medizin, 199, 273.

Felsenreich, G. and von Wiesner, R. (1915). Ueber Veränderungen an funktionstüchtigen Herzklappen. Frankfurter Zeitschrift für Pathologie, 18, 1.

Fernex, M. and Fernex, C. (1958). La dégénérescence mucoïde des valvules mitrales; ses répercussions fonctionelles. Helvetica Medica Acta, 25, 694.

McKusick, V. A. (1955). The cardiovascular aspects of Marfan's syndrome; a heritable disorder of connective tissue. Circulation, 11, 321. 
Pomerance, A. (1965). Pathology of the heart with and without cardiac failure in the aged. British Heart Journal, 27, 697.

Pomerance, A. (1967). Ageing changes in human heart valves. British Heart Journal, 29, 222.

Pomerance, A. (1969). Ballooning deformity (mucoid degeneration) of atrioventricular valves. British Heart Journal, 31, 343.

Raftery, E. B., Oakley, C. M., and Goodwin, J. F. (1966). Acute subvalvar mitral incompetence. Lancet, 2, 360.

Read, R. C., Thal, A. P., and Wendt, V. E. (1965). Symptomatic valvular myxomatous transformation, (the floppy valve syndrome). Circulation, 32, 897.

Shankar, K. R., Hultgren, M. K., Lauer, R. M., and Diehl, A. M. (1967). Lethal tricuspid and mitral regurgitation in Marfan's syndrome. American Journal of Cardiology, 20, 122.

Sinclair, R. J. G., Kitchin, A. H., and Turner, R. W. D. (1960). The Marfan syndrome. Quarterly Journal of Medicine, 29, 19.

Tobin, J. R., Bay, E. B., and Humphreys, E. M. (1947). Marfan's syndrome in the adult. Archives of Internal Medicine, 80, 475.

Tung, H. L. and Liebow, A. A. (1952). Marfan's syndrome. Laboratory Investigation, 1, 382.

Weill, G. (1932). Ectopie des cristallins et malformations générales. Annales d'Oculistique, 169, 21.

Requests for reprints to: Dr. P. Collins, The Royal $\delta^{\circ}$ Hospital, West Street, Sheffield 1. 